\title{
Bioceramic cement in endodontic fillings: a randomized clinical trial
}

\begin{abstract}
Statement of the problem: The bioceramic cements have properties that provide periradicular and root regeneration. Attributes that determine regenerative dentistry.

Purpose: the objective of this study was to evaluate endodontic treatments of necrotic teeth performed with PBS HP CIMMO ${ }^{\circledR}$ cement (without gutta-percha), compared to conventional treatments, filled with gutta-percha.

Materials and method: A two-arm, double-blind, single-center, randomized, and prospective clinical trial was designed (NCT03514264). CONSORT guidelines were followed. Eighty-six patients aged 18-60 years were enrolled; only one tooth per patient was treated. Patients were treated in two sessions in Group A (gutta-percha thermoplasticization and vertical hydraulic compresssion and AH Plus ${ }^{\circledR} n=43$ ) and one session in Group B (PBS HP CIMMO $\left.{ }^{\circledR} n=43\right)$. The evaluation was performed one year after the treatment. Two examiners performed clinical examinations and evaluated CT images for the presence or absence of periradicular lesion. Intention-to-treat analysis was used.
\end{abstract}

Results: Tomographic analyzes showed differences between the groups: group B (PBS HP $\left.\mathrm{CIMMO}^{\circledR}\right)$ presented a higher number of cases with periradicular regeneration $(\mathrm{p}=0.0004)$.

Conclusion: The results of the present study indicated the possibility of rehabilitation of necrotic teeth through endodontic filling with bioceramic (PBS HP CIMMO ${ }^{\circledR}$ ), without gutta-percha, in a single session.

Keywords: endodontic canal system, biomaterials, endodontic dentin system, periapical periodontitis, dental materials
Volume II Issue 3 - 2020

\author{
Rúbia Moura Leite Boczar,' Daniela \\ Francescato Veiga,' 'Yara Juliano, ${ }^{2}$ Taylor \\ Brandão Schnaider,' José Dias da Silva Neto' \\ 'Student of Professional Master's Program in Science Applied of \\ Health, University of Vale do Sapucaí, Brazil \\ 2Department of Biostatistics, University of Vale do Sapucaí,Brazil
}

Correspondence: Jose Dias da Silva Neto, Professional Master's Program in science Applied of Health, Universidade do Vale do Sapucaí, Pouso Alegre-MG, Av. Prefeito Tuany Toledo 470, Fátima I, CEP 37550-000, Brazil, Tel 5535-344-99248, 5535984321520,Email jdendod@yahoo.com.br

Received: May 07, 2020 | Published: June 17, 2020
Abbreviations: GP, guttapercha; BECs, bioactive endodontic cements; PUI, passive ultrasound irrigation; CT, computed tomography; Univás, university of vale do sapucaí; ASA, american society of anesthesiologists; physical fitness classification; $X^{2}$, Chi square test; $p$, statistical hypothesis testing

\section{Introduction}

The pathogenesis of the infection endodontic is complex and requires treatment that rehabilitates the root with hermetic sealing, determine to regression of the lesion, and ensures tooth regeneration while avoiding re-infection. ${ }^{1-5}$

There are two methods of endodontic treatment of necrotic teeth: single session and double session. Double session treatment involves introducing intra-canal medication into the root canals and temporary tooth restoration for 4 weeks, after which, endodontic obturation is performed in the second session. The most commonly used intracanal medication in endodontics is calcium hydroxide. ${ }^{6-9}$

The obtaining airtight obturation of root canals is the goal of endodontic treatment, promoting proper rehabilitation that prevents re-infection and provide regression of alveolar lesions. ${ }^{1}$ The most common technique for endodontic filling is using guttapercha (GP) cones (a thermoplastic material containing $70 \%$ zinc oxide) along with cement. ${ }^{10}$ This material occupies approximately $75 \%$ of the canal volume, while the remaining $25 \%$ is filled with cement. ${ }^{11}$
Gutta-percha is a biocompatible element; however, there is evidence of its longterm degradation, a situation that favors reinfection. ${ }^{12}$ For this reason, there is controversy regarding the execution of this technique (gutta percha and cement) in a single session. Thus, it is recommended to perform the procedure for necrotic teeth in two sessions. In the initial session, after instrumentation, the intra-canal medication is installed for a period of four weeks, which determines alkalinization and degradation of microbiota in the dentinal canaliculi. ${ }^{13}$

There are several types of cement available on the market, routinely incorporated to GP cones in endodontic filling. The most commonly used cements are resin cements such as AHPlus Dentsply ${ }^{\circledR}{ }^{10}$ and ready-to-usebioceramic cements such as BC Sealer EndoSequence ${ }^{\circledR} .{ }^{14}$ Resin cements have favorable properties such as biocompatibility, flowability and channel adhesion and GP, but are not bioactive. ${ }^{10}$

Ready-to-use bioceramics show bioactivity, but their longevity after obturation and degree of adhesion are controversial because they are ready for use and do not require mixing or the use of activators. This hydrophilic material is derived from calcium silicate and is incorporated into polymers for increased flow, but requires water to harden. These bio-cements make up less than a third of the total filling material used during obturation because most of the canal is filled with GP. ${ }^{10-15}$

Bioactive calcium silicate cements provide an innovative perspective on endodontic treatment because of their property of 
volumetric expansion and their ability to trigger the nucleation of hydroxyapatite deposits to reduce marginal porosities and seal discrepancies between the dentin and the obturation material. ${ }^{16,17}$

These bioactive endodontic cements (BECs) are considered synthetic dentin because they facilitate root and periradicular regeneration and establish definitive alkalinization of the root, rendering the environment inhospitable to microbial proliferation. ${ }^{18}$ The regeneration is established on two root surfaces: external (periodontal ligament and alveolar bone) and internal (cement and dentinal wall). ${ }^{18-21}$

Recent studies have developed a bioactive cement with the addition of adjunctive materials, which are important to create a strong material that can resist masticatory forces. This cement is called PBS HP CIMMO ${ }^{8}$. Composed of mineral oxides in the form of fine hydrophilic particles. It has excellent marginal sealing capacity and alkaline $\mathrm{pH}$ that prevent the migration of microorganisms and fluids into the root canal. Composition: $\mathrm{SiO}_{2}, \mathrm{~K}_{2} \mathrm{O}, \mathrm{Al}_{2} \mathrm{O} 3, \mathrm{Na}_{2} \mathrm{O}, \mathrm{Fe}_{2} \mathrm{O}_{3}$, $\mathrm{SO}_{3}, \mathrm{BaSO}_{4}, \mathrm{CaO}, \mathrm{MgO}$. A national patent application has been filed in the National Intellectual Property Institute (registration number: BR 102017 022748). Experimental studies have been performed to define the regenerative capacity of PBS HP CIMMO ${ }^{\circledR}$ cement in furcation lesions..$^{22,23}$

Clinical studies with PBS HP CIMMO ${ }^{\circledR}$ cement have been carried out to evaluate the regeneration of teeth subjected to parendodontic surgery. ${ }^{24,25}$ The results of these studies have demonstrated that the clinical use of PBS HP CIMMO ${ }^{\circledR}$ cement is feasible because it facilitates regeneration of bone and periodontal ligament structures in the long-term and is more resistant to masticatory forces due to the presence of additives. ${ }^{24,25}$

Therefore, the objective of this study was to evaluate endodontic treatments of necrotic teeth performed with PBS HP CIMMO ${ }^{\circledR}$ cement (without gutta-percha), compared to conventional treatments, filled with gutta-percha. ${ }^{20,21,24-25}$

\section{Materials and method}

This study was a randomized, non-inferiority trial, two-arm, double-blind, single-center trial that was conducted from November 2017 to June 2019 at the Endodontics Clinic of the Brazilian Association of Dentistry at Vale Sapucaí University (Univás), Pouso Alegre, Minas Gerais, Brazil.

The project was approved by the Ethics Committee of the Univás, mind $\mathrm{n}^{\mathrm{o}}$, CAAE-77495717.7.0000.5102. The study was enrolled at ClinicalTrials.gov (NCT 03514264). The financing obtained to carry out the study was by the Company MJS Industry and Commerce of Materials for Health ltda cnpj: 24.752.361/0001-52.

It was calculated the sample size using the Lee Sample software by comparing two proportions with a dichotomous response. As a parameter, it was cosidered the failure index for the endodontic obturation technique with cement and gutta-percha at $20 \%$. $^{26-28}$ The researchs by Silva Neto et al. ${ }^{20-22,25}$ were used as a parameter to define the percentage of failure for the (PBS HP CIMMO ${ }^{\circledR}$ Pouso Alegre, Minas Gerais, Brazil) group at $10 \%$. The test was considered monocaudal with a test power of $90 \%$ and a level of significance of $5 \%$, was allocated 43 patients per group.
The primary outcome of the study was to assess the presence or absence of periradicular injury by cone beam computed tomography after one year of treatment.

The secondary outcome was the clinical examination: presence of fistula, pain on apical palpation and percussion.

The Endodontics Team of the Univás Graduate Clinic examined the patients through anamnesis, clinical examination and radiographic. Inclusion criteria were as follows; age: 18-60 years, gender: male or female. The preoperative diagnosis was made through clinical and radiographic exams that showed pulp necrosis with the presence of periapical lesions, one tooth per patient. Single root or multiple roots and all with periapical lesion. The preoperative images were radiographic due to the high cost of tomography. It was decided to perform CT scans only after one year. The exclusion criteria were as follows; patients who did not agree to participate in the study and/ or who did not sign the informed consent form, pregnant women, patients with periodontal disease and patients with ASA III, IV and V status (American Society of Anesthesiologists; physical fitness classification). Patients were allocated into 2 groups, A or B, at a 1:1 ratio according to a random computer generated sequence by Randomization.com (https://www.randomization.com).

Opaque envelopes, sequentially sealed and numbered, containing the group name, as well as the material to be used for each patient, were used to ensure allocation confidentiality. Each envelope was delivered to the professional who performed the intervention, at the initial moment of care. In all, 4 professional dental surgeons specializing in endodontics performed the interventions.

The professionals who treated group A subjects (gutta-percha) instructed their patients, after the first session, to return 30 days later for their second obturation session. Group B patients (PBS HP CIMMO ${ }^{\circledR}$ Pouso Alegre, Minas Gerais, Brasil) underwent the intervention in a single session.

The 86 patients were instructed to return one year after endodontic obturation, for clinical examinations and cone-beam computed tomography. Clinical examinations and tomography analyzes, were performed, independently by 2 endodontist examiners with more than 20 years of clinical experience.

In order to ensure participants' adherence to the research, free preventive dental care was offered to all patients who returned for the collection of results.

The recommended techniques for each group are as follows:

Group A - Endodontic obturation with (AHPlus Dentsply ${ }^{\circledR}$ Pirassununga, São Paulo, Brazil) Cement and Gutta-percha (Dentsply® Pirassununga, São Paulo, Brazil).

First session: Anesthesia was administered with (Articaine, DFL ${ }^{\circledR}$ Industry and Commerce- Taquara, Rio de Janeiro, Brazil), opening and absolute isolation. Then, instrumentation, intra-canal medication installation and temporary restoration with (Fgm Maxxion R A2 ${ }^{8}$ Cruzeiro, São Paulo, Brazil), were performed.

The endodontic instruments used for the instrumentation were: manual instruments (K 10 Dentsply ${ }^{\circledR}$ Pirassununga, São Paulo, Brazil) and mechanized instruments (Prodesign Logic Easy ${ }^{\circledR}$ Belo 
Horizonte, Minas Gerais, Brazil), according to the needs of the tooth to be treated $(2501,1505,2504,2505)$, coupled to the endodontic motor (Easy SI ${ }^{\circledR}$ Belo Horizonte, Minas Gerais, Brazil).

The crown-down instrumentation technique was used, dentistry was performed with Novapex ${ }^{\circledR}$ appliance and the final foraminal dilation was (25). The auxiliary chemical solution for irrigation was $5.5 \%$ sodium hypochlorite. Passive ultrasound irrigation (PUI) (Dabi Atlante ProfiNeo® Ribeirão Preto, São Paulo, Brazil) and ultrasonic tip (ESI 015 - Trinks ${ }^{\circledR}$ Pirituba, São Paulo, Brazil) with 5.5\% sodium hypochlorite and EDTA T (Formula \& Action ${ }^{\circledR}$ São Paulo, São Paulo, Brazil) were performed at the end of the instrumentation. Intracanal medication (Callen PMCC SSWhite ${ }^{\circledR}$ ) was then placed into the canals by syringe (ML Endodontic SSWhite ${ }^{\circledR}$ Rio de Janeiro, Rio de Janeiro, Brazil) and the tooth was provisionally restored with restorative glass ionomer (Fgm Maxxion R A2 ${ }^{\circledR}$ Cruzeiro, São Paulo, Brazil).

The systemic medication administered followed the determination of each case. When there was systemic involvement and acute inflammatory process, amoxicillin+potassium clavulanate $875 \mathrm{mg}, 1$ tablet every 12 hours for 7 days, was prescribed. In case of allergy to amoxicillin, $300 \mathrm{mg}$ of clindamycin, 1 capsule every 8 hours for 7 days, was prescribed. The antiinflammatory drug of choice was dexamethasone $4 \mathrm{mg}, 1$ tablet every 12 hours for 3 days or $400 \mathrm{mg}$ nimesulide, 1 tablet every 12 hours for 3 days for patients in whom dexametazone was contraindicated. The second session occurred 4 weeks after the first.

\section{Second session (endodontic obturation)}

After 30 days, ${ }^{6,79,13}$ patients in group A returned to the obturation session. The same anesthesia and absolute isolation procedures were performed. After temporary removal of the restoration, intracanal medication was withdrawn by irrigation with $5.5 \%$ sodium hypochlorite and use of the final instrumentation file. The canals were dried with absorbent paper cones and the main gutta-percha cones were coupled to the channels with final calibration (25). Cone-proof radiography was performed to certify calibration. After handling thecement (AHPlus Dentsply $\left.{ }^{\circledR}\right)$, the gutta-percha cones were inserted into the channels associated with the cement. The filling endodontic technique performed was gutta-percha thermoplasticization and vertical hydraulic compression using a device (Touch ' $\mathrm{n}$ Heat ${ }^{\mathrm{TM}}$ 5004 SybronEndo Orange, CA 92867, EUA). After cleaning the pulp chamber, the teeth were restored with composite resin and the patients were instructed to return to proservation.

Group B - Endodontic obturation with PBS CIMMO HP® Cement.

\section{Single session}

The pacients of Group B received the same treatment as group A: anesthesia, coronary opening, absolute isolation, endodontic instrumentation technique, auxiliary chemicals $(5.5 \%$ sodium hypochlorite and EDTA T Formula \& Action $\left.{ }^{\circledR}\right)$ and PUI. The canals were dried with absorbent paper cones and filled with PBS HP CIMMO ${ }^{\circledR}$ cement as a single shutter element.

The endodontic fillings with PBS CIMMO HP ${ }^{\circledR}$ were performed according to the following protocol: one cement portion and two drops of distilled water were dispensed onto a glass plate. Agglutination of the cement in the water was performed using a flexible spatula number
24 (Duflex® Rio de Janeiro, Rio de Janeiro, Brazil); it was followed manufacturer's recommendations, up to to achieve consistency (flow). The Macspaden (Flex Pack Easy ${ }^{\circledR}$ Belo Horizonte, Minas Gerais, Brazil) instruments, coupled to the micro engine of the dental office intra system, were used to install the intra canal cement. Schilder (double niti Easy ${ }^{\circledR}$ Belo Horizonte, Minas Gerais, Brazil) condensers were used to condense the intra canal cement. These instruments are calibrated according to the anatomy of each instrumented channel: green $(0.35$ and 0.70$)$, black (0.40 and 0.80$)$, yellow (0.50 and 1.00) and blue $(0,60$ and 1.20$)$.

Similar to group A, the teeth were restored with composite resin. Systemic medication was only used in acute cases with systemic involvement and followed the same protocol as group A.

After one year, both group A and group B patients returned to the endodontic clinic for clinical examinations, which were performed by two endodontists with more than twenty years of experience, independently and blinded to the group to which the patient participated. The patients were referred for tomographic exams. The analysis of the tomographic exams was performed by the two endodontists independently and blind to the group belonging. The gray scale was used to characterize the CT image, since the preoperative images were radiographic due to the high cost of the tomography.

\section{Statistical analysis}

For categorical variables (gender, presence or absence of fistula, presence or absence of periapical lesion, analyzed by tomography), the chi-square test was applied. Analyzes were performed using the Bioestat ver program. 5.3 (Mamirauá Institute, Pará and Amazonas, Brazil) and the significance level was set at $\mathrm{p}=0.05$ or $5 \%$.

\section{Results}

43 patients were allocated to each group. There were 9 losses, 3 in group A and 6 in group B. These patients did not return to the examination after one year (Figure 1).

There was no significant difference between groups in terms of gender, age, location [intraoral (upper or lower arch)] or number of roots of treated teeth.

Two evaluators independently performed clinical examinations and found no clinical evidence determined in the secondary outcome of the present study. They evaluated the cone beam computed tomography and disagreed with the CT findings in two cases treated in group B, but agreed with $100 \%$ confirmation of the positive results after a consensus meeting.

Table 1 shows the comparison between the groups regarding tomography. There was significance $(\mathrm{p}=0.004)$ for group $\mathrm{B}$.

Figure 2 shows a failure related to the presence of periapical lesion (primary study outcome).

In group A and Figure 3 shows success in group B (absence of periapical lesion, also related to the primary outcome). The intentionto-treat analysis method was used (patients who did not show up for evaluation after one year of treatment were considered unsuccessful for the statistical analysis: 3 for group A and 6 for group B. 


\section{CONSORT

CONSORT 2010 Flow Diagram

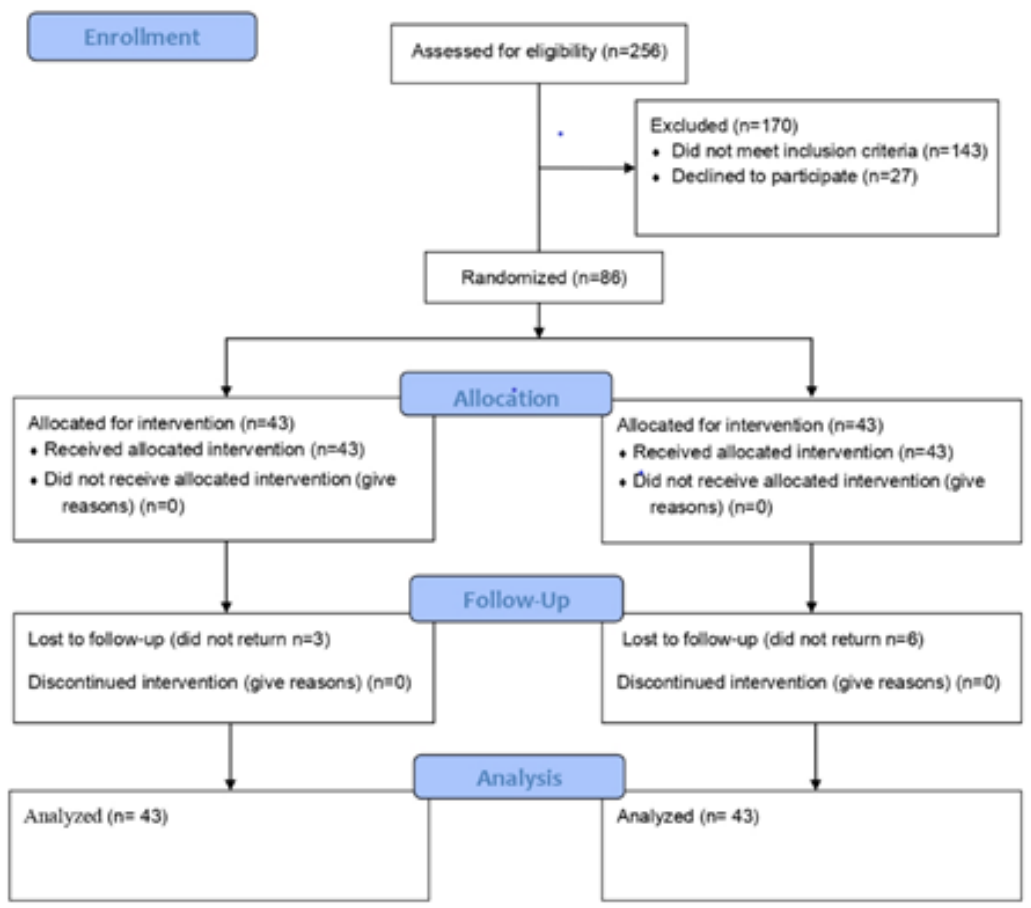

Figure I Consort 2010 flow diagram
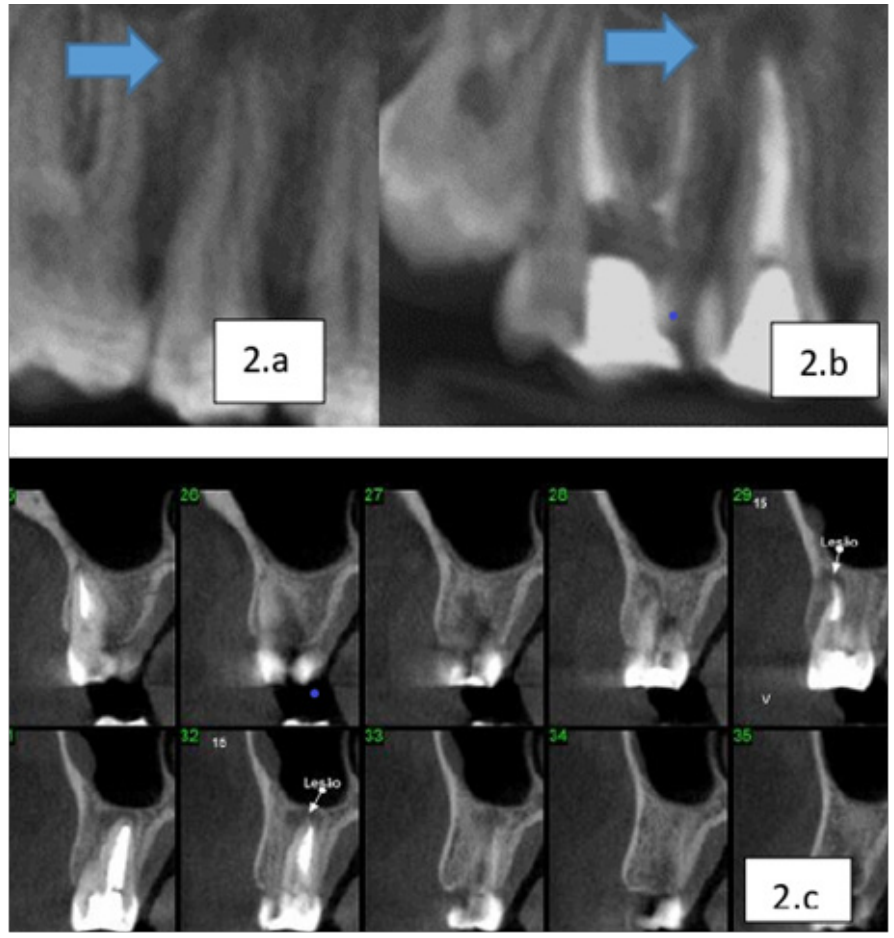

Figure 2 Tooth 2.5 of patient 27 (group A).2(A)Periapical radiography before treatment.2 (B) Periapical radiography immediately after treatment; (arrows indicate periapical lesion).2 (C)Cone beam tomography one year later, with presence of periapical lesion. 


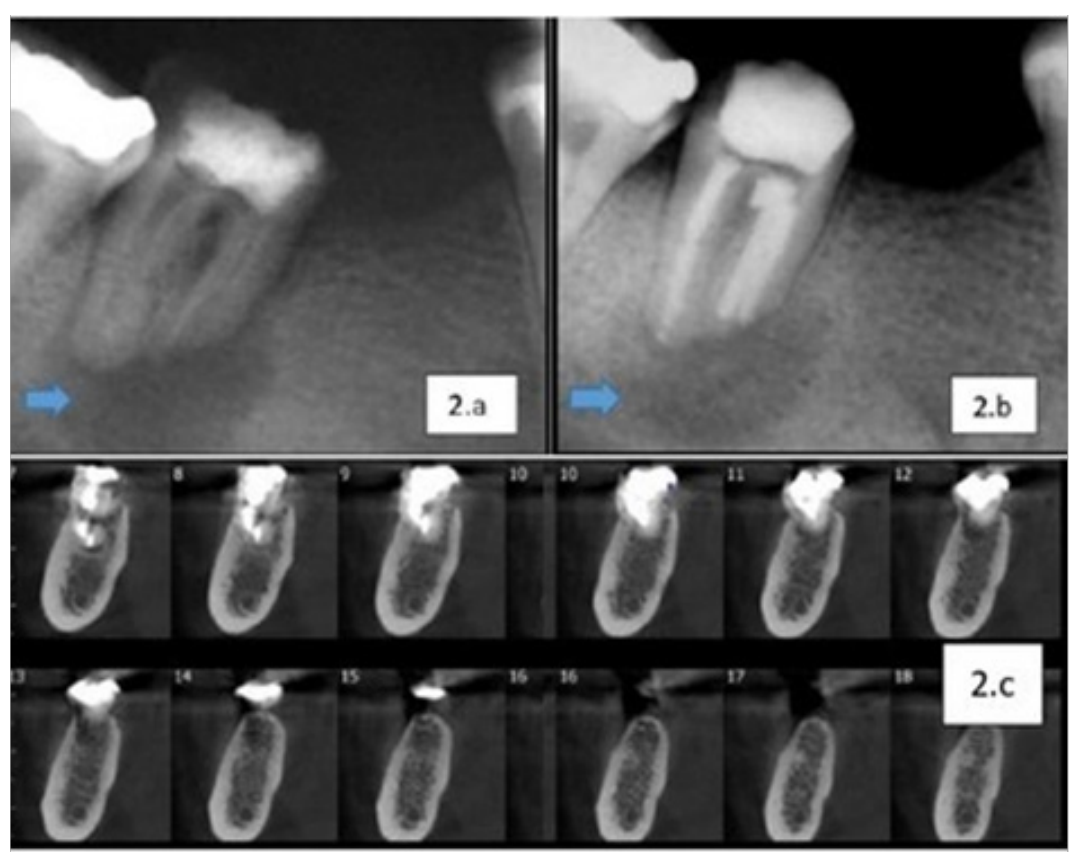

Figure 3 tooth 4.7 of patient 35 (group B). 2 (A) Periapical radiography before treatment. 2 (B) Periapical radiography immediately after treatment; (arrows indicate periapical lesion). 2 (C) Cone beam tomography one year later, with presence of periapical lesion.

Table I Comparison of groups A and B: comparison between the groups on computed tomography

\begin{tabular}{llll}
\hline & \multicolumn{3}{l}{$\mathbf{n}(\%)$} \\
\cline { 2 - 4 } & Failure & Success & Total \\
\hline Group A & 8 & $35(43)$ & 43 \\
Group B & 0 & $43(43)$ & 43 \\
Total & 8 & $78(86)$ & 86 \\
$\begin{array}{l}\text { Group A x Group B } \\
\text { (Chi-square test) }\end{array}$ & $X^{2}=0.00 ; p=0.004$ & \\
\hline
\end{tabular}

\section{Discussion}

Standard endodontic obturation consists of combining endodontic cement with gutta-percha (GP) cones. GP is an inert material and represents $75 \%$ of the volume of the obturation, while the remainder $25 \%$ of the obturation consists of cement that connects the GP to the canal walls, sealing the empty areas and providing uniformity. ${ }^{29}$

GP's modern thermoplasticization techniques require the use of thermoplastic agents that heat the GP cones and condense the cement and GP assembly in the root canal. ${ }^{4}$ It is important to ensure that the endodontic obturation does not overflow into the periradicular region. Trans-surgical radiographs are routinely performed during the obturation process to analyze the calibration of the main GP cones. This procedure requires attention, dexterity and time to perform..$^{20,21}$

The aim of the present study was to determine the viability of the new material for endodontic filling in order to overcome the limitations of conventional techniques, especially in relation to the regenerative effect on dental tissues. Conventional filling with guttapercha and conventional cements does not reestabelecem to the tooth the bioactive action and resistance that bioceramic cements can provide. ${ }^{7-13}$
Most of the other cements that accompany GP in endodontic obturation are not biocompatible. Therefore, when the accuracy of extravasation of the filling into the periradicular space is questionable, these cements may cause chemical and traumatic pericementitis. Only a few of these cements are considered biocompatible, such as the resin cement AH Plus Dentsply®.,30,31

The choice of AH Plus Dentsply® cement for Group A, is justified because it has the properties required by the conventional technique. New cements, such as premanipulated endodontic bioceramics, have been shown to have problems with polymerization and adhesion when used in association with GP in the standard technique. ${ }^{32,33}$ The problem may be related to the presence of polymers and aqueous gel in premanipulation. The manufacturers propose that dentinal fluid in the roots is responsible for the intra-channel polymerization of cement, but this fluid is not only composed of water and bioceramics require water for polymerization. ${ }^{34,35}$

The procedure recommended in this study (PBS HP CIMMO ${ }^{\circledR}$ bioceramic cement monobloc filling) does not require additional devices to perform. There is also no indication for the use of intraoperative radiographs, since extravasation of the material beyond the apical foramen is not a concern due to the bioactive and regenerative properties of bioceramics. These factors lead to the optimization of working time, which is directly proportional to the improvement of patient and professional quality of life. ${ }^{20-25}$

Conventional obturation techniques do not take into account the advantage of bioactivity exhibited by bioceramic cements. This context is extremely important because bioactivity creates an alkalineenvironment in the sealed channel that becomes inhospitable to microbial survival and proliferation. Persistent and secondary infections do not manifest if the canal environment remains alcaline. ${ }^{31}$ In addition, standard techniques are not capable of promoting root regeneration because conventional cements associated the GP are not bioactive. Conventional endodontic obturation of cement and GP is 
not a precursor to the formation of carbonated apatites that promote biomineralization, which is an attribute of bioceramic cements. ${ }^{19-18,31}$

This discussion also takes into account the difficulty of performing the procedure in two sessions. Initially due to recommendations from Brazilian authors that indicate the use of intracanal medication with calcium hydroxide for 4 weeks, a controversial procedure in the endodontic environment. ${ }^{6,7,9,13}$; which requires conditioning of the patient, anesthesia, isolation of the operative and postoperative field twice. Another relevant factor is the need to use temporary restorative material for dental crowns, which can fracture and suffer marginal microleakage during the interval between sessions. Group B was treated in a single session, which optimized the technique and provided a single postoperative recovery period for patients. The advantages of changing the treatment protocol for necrotic teeth include, in addition to the factors above, the biomineralization identified in group B patients.

The raw material used to make bioceramic cements is calcium silicate. The first bioceramic in dentistry was MTA (Mineral Aggregate Trioxide), which in addition to the raw material contains bismuth oxide, a radiopacifying agent that decreases the resistance of bioceramic cement to masticatory forces. ${ }^{5}$ Recent studies have shown the development of HP CIMMO ${ }^{\circledR}$ PBS cement with the same MTA base, but with biomimetic additives and radiopacifiers that do not interfere with cement strength, which is important to support mastication forces. ${ }^{22,23}$ The computed tomography of the present study demonstrated periapical regeneration in the teeth treated with PBS HP CIMMO ${ }^{\circledR}$ cement (primary outcome of the study) and the results indicate the possibility of using this bioceramics as the only element in endodontic filling.

There were 9 losses during the study: 3 from group A and 6 from group B. Despite the losses, group B showed superior results in relation to periradicular regeneration, with statistical significance determined for the primary outcome of the study, which shows the possibility of this protocol to use the PBS HP CIMMO ${ }^{\circledR}$ cement in a single session on necrotic teeth to be used.

The limitation of the proposed study is determined by the lack of clinical studies using this material, especially if performed by authors who are not linked to the development of this new cement, as well as the impossibility of performing tomography as a preoperative exam. Further research is being conducted by researchers from different universities.

\section{Conclusion}

The results of the present study indicated the possibility of rehabilitation of necrotic teeth through endodontic filling with bioceramic (PBS HP CIMMO ${ }^{\circledR}$ ), without gutta-percha, in a single session.

\section{Funding}

None.

\section{Acknowledgments}

The authors thank MJS for their sponsorship.

\section{Conflicts of interest}

The authors declare no conflicts of interest related to this study.

\section{References}

1. Rôças IN, Siqueira JF Jr. Frequency and levels of candidate endodontic pathogens in acute apical abscesses as compared to asymptomatic apical periodontitis. PLoS One. 2018;13(1):e0190469.

2. Wilson CE, PC Cathro, Rogers AH, et al. Clonal diversity in Enterococcus faecalis biofilm formation in response to environmental stress associated with irrigants and endodontic drugs. Int Endod J. 2015;48(3):210-219.

3. Zandi H, Kristoffersen AK, Orstavik D, et al. Microbial analysis of endodontic infections in root-filled teeth with apical periodontitis before and after irrigation using pyrosequencing. J Endod. 2018;44(3):372-378.

4. Alves FRF, Paiva PL, Marceliano-Alves MF, et al. Bacteria and hard tissue debris extrusion and intracanal bacterial reduction promoted by XPendo shaper and reciproc instruments. J Endod. 2018;44(7):1173-1188.

5. Takahama A Jr, Rôças IN, Faustino ISP, et al. Association between bacteria occurring in the apical canal system and expression of boneresorbing mediators and matrix metalloproteinases in apical periodontitis. Int Endod J. 2018;51(7):738-746.

6. Leonardo MR, Silveira FF, Silva LA, et al. Calcium hydroxide root cana dressing. Histopathological evaluation of periapical repair at different time periods. Braz Dent J. 2002;13(1):17-22.

7. Holland R, Otoboni Filho JA, de Souza V, et al. A comparison of one versus two appointment endodontic therapy in dogs' teeth with apical periodontitis. J Endod. 2003;29(2):121-124.

8. Moreira MS, Anuar ASN, Tedesco TK, et al. Endodontic treatment in single and multiple visits: an overview of systematic reviews. $J$ Endod. 2017;43(6):864-870.

9. Saatchi M, Shokraneh A, Navaei H, et al. Antibacterial effect of calcium hydroxide combined with chlorhexidine on Enterococcus faecalis: a systematic review and meta-analysis. Journal of Applied Oral Science. 2014;22(5):356-365.

10. Mokhtari H, Rahimi S, Forough Reyhani M, et al. Comparison of pushout bond strength of gutta-percha to root canal dentin in single-cone and cold lateral compaction techniques with ah plus sealer in mandibular premolars. J Dent Res Dent Clin Dent Prospects. 2015;9(4):221-225.

11. Celikten B, Uzuntas CF, Orhan AI, et al. Evaluation of the quality of the endodontic cement filling using a single cone technique in oval channels: A micro-CT study in vitro. Wiley Periodicals, Inc. 2016;38(2):133-140.

12. Maniglia-Ferreira C, Bönecker G, Silva Jr JB, et al. Transpolyisoprene degradation after root filling with thermoplastic techniques. Int Endod J. 2008;41:296-302.

13. Leonardo MR, Hernandez ME, Silva LA, et al. Effect of a calcium hydroxide-based root canal dressing on periapical repair in dogs: a histological study. Oral Surg Oral Med Oral Pathol Oral Radiol Endod. 2006;102(5):680-685

14. El Hachem R, Khalil eu, Le Brun L, et al. Penetration of the dentin tubules of AH Plus, BC Sealer and a new tricalcium silicate sealant: a confocal microscopy study of laser scanning.Clin Oral Investig. 2018;40(11):1-7.

15. Carvalho CN, Grazziotin-Soares R, Miranda Candeiro GT, et al. Micro strength bond push-out and bioactivity analysis of a bioceramic root canal sealer. Iran Endod J. 2017;12(3):343-348.

16. Prati C, Gandolfi MG. Calcium silicate bioactive cements: biological perspectives and clinical applications. Mater Dent. 2015;31(4):351-370.

17. Torabinejad M, Parirokh M, Dummer PMH. Mineral trioxide aggregate and other bioactive endodontic cements: an updated overview part II: other clinical applications and complications. Int Endod J. 2018;51(3):284-317. 
18. Bakhtiar H, Nekoofar MH, Aminishakib P, et al. Human Pulp Responses to Partial Pulpotomy Treatment with TheraCal as Compared with Biodentine and ProRoot MTA: A Clinical Trial. J Endod. 2017;43(11):1786-1791.

19. Parirokh M, Torabinejad M, Dummer PMH. Mineral trioxide aggregate and other bioactive endodontic cements: an updated overview - part I: vital pulp therapy. Int Endod J. 2018;51(2):177-205.

20. Boczar RML, Silva SR, Alves LO, et al. Single Element In Obturation With Endodontic Retreatment With PBS ${ }^{\circledR}$ CIMMO Cement In Alveolar Tooth Abscess - Case Report. Wulfenia. 2018;25(2):119-128.

21. Silva SR, Filho IJZ, Silva Neto JD. Incomplete rhizogenesis and necrosis treated with PBS ${ }^{\circ}$ HP cement synthetic barrier: case report. $J$ Dent Health Oral Disord Ther. 2018;9(3):205-208.

22. Silva Neto JD, Brito RH, Schnaider TB, et al. Root perforations treatment using mineral trioxide aggregate and Portland cements. Acta Cir Bras. 2010;25(6):479-484.

23. Silva Neto JD, Schnaider TB, Gragnani A, et al. Portland cement with additives in the repair of furcation perforations in dogs. Acta Cir Bras. 2012;27(11):809-814.

24. Silva SR, Silva Neto JD, Novo NF, et al. Portland cement versus MTA as a rootend filling material. A pilot study Acta Cir Bras. 2015;30(2):160-164.

25. Silva SR, Silva JD Neto, Schnaider TB, et al. The use of a biocompatible cement in endodontic surgery. A randomized clinical trial. Acta Cirurgica Brasileira. 2016;31(6):422-427.

26. Ricucci D, Siqueira JF Jr. Biofilms and apical periodontitis: study of prevalence and association with clinical and histopathologic findings. $J$ Endod. 2010;36(8):1277-1288.

27. Signoretti FG, Endo MS, Gomes BP, et al. Persistent extraradicular infection in root-filled asymptomatic human tooth: scanning electron microscopic analysis and microbial investigation after apical microsurgery. J Endod. 2011;37(12):1696-1700.
28. Werlang AI, Baldissarelli F, Werlang FA, et al. Insucesso no Tratamento Endodôntico: Uma Revisão de Literatura. Revista Tecnológica. 2016;5(2):31-47.

29. Moher D, Schulz KF, Altman D. The CONSORT Group. Consolidated Standards of Reporting Trials. The CONSORT statement: revised recommendations for improving the quality of reports of parallel-group randomized trials. JAMA. 2001;357(9263):1191-1994.

30. Van der Sluis LW. Endodontics in motion: new concepts, materials and techniques. The role of irrigants during root canal treatment. Ned Tijdschr Tandheelkd. 2015;122(10):533-538.

31. Kok D, Rosa RA, Barreto MS. Penetrability of AH plus and MTA fillapex after endodontic treatment and retreatment: a confocal laser scanning microscopy study. Microsc Res Tech. 2014;77(6):467-471.

32. Akcay M, Arslan H, Durmus N, et al. Dentinal tubule penetration of AH Plus, iRoot SP, MTA fillapex, and guttaflow bioseal root canal sealers after different final irrigation procedures: A confocal microscopic study. Laser Surg Med. 2016;48(1):70-76.

33. Dabaj P, Kalender A, Unverdi E A. Push-Out Bond Strength and SEM Evaluation in Roots Filled with Two Different Techniques Using New and Conventional Sealers. Materials (Basel). 2018;11(9):1-10.

34. Khabbaz MG, Anastasiadis PL, Sykaras SN. Determination of endotoxins in caries: association with pulpal pain. Int Endod J. 2000;33(2):13-27.

35. Castro AL, Libório JBL, Pandolfelli VC. The influence of cement type on the performance of advanced concretes designed by computing mix proportion technique. Cerâmica. 2011;57(341):10-21. 